\title{
Penetrating injury of the heart by a nail gun
}

\author{
Ercan Eren, MD, Cüneyt Keles, MD, Basar Sareyyupoglu, MD, Nilgun Bozbuga, MD, Mehmet Balkanay, MD, and \\ Cevat Yakut, MD, İstanbul, Turkey
}

$\mathrm{N}$ ail-gun injuries may occur accidentally or be selfinflicted. The most commonly affected area in the heart is the right ventricle because of its anterior location to the chest. Although these injuries are considered survivable in the modern era, expedient surgery and timing of intervention are critical for obtaining good results.

\section{Clinical Summary}

A 37-year-old construction worker was sent to the emergency service for an accidental nail-gun shot injury of the chest. At admission, he was noted to be alert; his blood pressure was 95/55 $\mathrm{mm} \mathrm{Hg}$ and his heart rate was 115 beats per minute. He had no murmur on auscultation. He was tachypneic with shallow respiration. On physical examination, there was a neat, almost circular puncture wound to the left of the sternum in the sixth intercostal space. Computed tomography showed a nail on the anterior surface of the heart (Figure 1). After fluid resuscitation, the patient was transported to our hospital. On arrival, the patient was conscious with tachypnea and blood pressure of 90/50 $\mathrm{mm} \mathrm{Hg}$. The patient was immediately transferred to the operating room. After intubation, a left anterior thoracotomy was performed in the sixth intercostal space. The pericardium was not dense and was opened. After releasing the small amount of pericardial fluids, examination of the heart revealed a nail penetrating the anterior surface of the right ventricle. There was no active bleeding. The nail was extracted under direct vision. A singlestitch repair of the right ventricular wound was performed with a Teflon-pledgetted 3-0 polypropylene suture. There was no exit wound on exploration of the whole heart. The pericardium was left open. One pericardial drain and 1 thoracic drain were placed. Postoperative course was uneventful. Postoperative 2-dimensional echocardiogram revealed no intracardiac shunt. The patient was discharged on postoperative day 5 in good condition.

\section{Comment}

Nail-gun injury of the heart is fairly rare. It may occur accidentally due to the common use of the nail gun in the construction industry. However, the incidence of reported self-inflicted cases has increased recently for unknown reasons. ${ }^{1}$ Although the most affected area is the

\footnotetext{
From the Koşuyolu Heart and Research Hospital, Department of Cardiovascular Surgery, İstanbul, Turkey.

Received for publication July 25, 2003; accepted for publication Sept 9, 2003.

Address for reprints: Ercan Eren, MD, Atıf Bey sok, Yeniköy Sitesi A3 Blok Daire 7 81020, Kosuyolu, İstanbul, Turkey (E-mail: dreren1@lycos.com).

J Thorac Cardiovasc Surg 2004;127:598

$0022-5223 / \$ 30.00$

Copyright $\odot 2004$ by The American Association for Thoracic Surgery doi:10.1016/j.jtcvs.2003.09.041
}

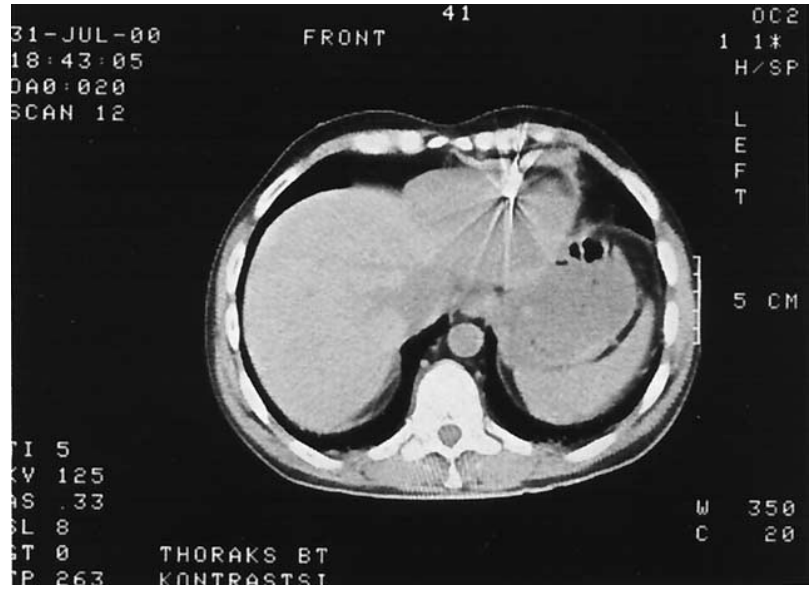

Figure 1. Computed tomography revealed a nail in the anterior myocardium of the heart.

right ventricle, the descending thoracic aorta may even be injured by a nail as in the case reported recently by Takagi and colleagues. ${ }^{2}$

In the literature, nail-gun injuries have $25 \%$ mortality, similar to that of stab wounds. ${ }^{1-3}$ Hence, nail-gun injury is considered a survivable condition among the penetrating cardiac injuries.

Treatment of penetrating cardiac injuries most often requires emergency operation. If there is no tamponade with stable hemodynamic parameters, conservative management can be done in many cases. Vosswinkel and Bilfinger ${ }^{1}$ reported penetrating cardiac nailgun injuries created tamponade with $73 \%$ of cases; all the patients received operative exploration in their review. Median sternotomy or thoracotomy can be performed depending on the location of the heart injury. In addition to surgery, fluid resuscitation is critical, particularly if the patient should be transferred to another center. Catarino and colleagues ${ }^{4}$ advocated controlled hypotension and avoiding blind bolus administration of intravenous fluids, especially during interhospital transfer of the patient with cardiac injury.

In conclusion, nail-gun injury of the heart is a rare condition, and expedient surgery and timing of intervention are critical for obtaining good results.

\section{References}

1. Vosswinkel JA, Bilfinger TV. Cardiac nail gun injuries: lessons learned. J Trauma. 1999;47:588-90.

2. Takagi H, Mori $\mathrm{Y}$, Murase K, Hirose H. Nail gun penetrating cardiac injury. Eur J Cardiothorac Surg. 2003;23:841.

3. Asensio JA, Berne JD, Demetriades D, et al. One hundred five penetrating cardiac injuries: a 2-year prospective evaluation. J Trauma. 1998;44:1073-82.

4. Catarino PA, Halstead JC, Westaby S. Attempted nail-gun suicide: fluid management in penetrating cardiac injury. Injury. 2000;31:209-11. 